OPEN ACCESS

Edited by:

Mohammad Amjad Kamal, King Abdulaziz University,

Saudi Arabia

Reviewed by:

Ana I. Duarte,

University of Coimbra, Portugal Christian J. Pike,

University of Southern California, USA

*Correspondence: Marcelo N. N. Vieira mnunes@bioqmed.ufrj.br Fernanda G. De Felice felice@bioqmed.ufrj.br

Received: 29 November 2016 Accepted: 12 January 2017 Published: 31 January 2017

Citation:

Vieira MNN, Lyra e Silva NM, Ferreira ST and De Felice FG (2017) Protein Tyrosine Phosphatase 1B (PTP1B): A Potential Target for Alzheimer's Therapy?

Front. Aging Neurosci. 9:7. doi: 10.3389/fnagi.2017.00007

\section{Protein Tyrosine Phosphatase 1B (PTP1B): A Potential Target for Alzheimer's Therapy?}

\author{
Marcelo N. N. Vieira ${ }^{1,2 *}$, Natalia M. Lyra e Silva ${ }^{1}$, Sergio T. Ferreira ${ }^{1,2}$ \\ and Fernanda G. De Felice ${ }^{1,3 *}$
}

\begin{abstract}
'Institute of Medical Biochemistry Leopoldo de Meis, Federal University of Rio de Janeiro, Rio de Janeiro, Brazil, 2Institute of Biophysics Carlos Chagas Filho, Federal University of Rio de Janeiro, Rio de Janeiro, Brazil, ${ }^{3}$ Centre for Neuroscience Studies, Department of Biomedical and Molecular Sciences, Queen's University, Kingston, ON, Canada
\end{abstract}

Despite significant advances in current understanding of mechanisms of pathogenesis in Alzheimer's disease (AD), attempts at drug development based on those discoveries have failed to translate into effective, disease-modifying therapies. AD is a complex and multifactorial disease comprising a range of aberrant cellular/molecular processes taking part in different cell types and brain regions. As a consequence, therapeutics for $A D$ should be able to block or compensate multiple abnormal pathological events. Here, we examine recent evidence that inhibition of protein tyrosine phosphatase 1B (PTP1B) may represent a promising strategy to combat a variety of $A D$-related detrimental processes. Besides its well described role as a negative regulator of insulin and leptin signaling, PTB1B recently emerged as a modulator of various other processes in the central nervous system (CNS) that are also implicated in AD. These include signaling pathways germane to learning and memory, regulation of synapse dynamics, endoplasmic reticulum (ER) stress and microglia-mediated neuroinflammation. We propose that PTP1B inhibition may represent an attractive and yet unexplored therapeutic approach to correct aberrant signaling pathways linked to $A D$.

Keywords: Alzheimer's disease, protein tyrosine phosphatase 1B, diabetes, synaptic plasticity, neuroinflammation, insulin signaling, leptin signaling, endoplasmic reticulum stress

\section{INTRODUCTION}

There are currently no disease-modifying therapies for Alzheimer's disease (AD), and treatments offer limited, temporary improvement in quality of life (Rafii and Aisen, 2015). This scenario drives scientists and pharmaceutical companies into an intense search for effective therapies for AD. Unfortunately, most if not all therapeutics that showed promise in preclinical models failed to translate into effective therapies, as evidenced by numerous unsuccessful clinical trials. Because $\mathrm{AD}$ comprises a broad range of deregulated processes taking place concomitantly, drugs acting on multiple aberrant processes hold promise as candidates for AD therapeutics. Herein, we discuss recent evidence indicating that protein tyrosine phosphatase 1B (PTP1B) inhibitors fulfill this criterion.

A pivotal event in $\mathrm{AD}$ pathogenesis is the buildup in the brain of amyloid- $\beta$ oligomers (A $\beta O s)$, neurotoxins that trigger synapse failure and lead to cognitive impairment (Ferreira and Klein, 2011; Ferreira et al., 2015; Selkoe and Hardy, 2016). In neurons, A $\beta$ Os attack synapses (Lacor et al., 2004), altering membrane receptor composition 
(Lacor et al., 2007; De Felice et al., 2009; Jürgensen et al., 2011), impairing synaptic plasticity (Lambert et al., 1998; Walsh et al., 2002), and ultimately leading to synapse loss. Several signaling pathways germane to learning and memory are affected by $A \beta O$ s. Some of those are initiated by receptor tyrosine-kinases (RTKs) such as the insulin receptor (IR; De Felice et al., 2009; Ma et al., 2009), the leptin receptor (LepR; Marwarha et al., 2011; Maioli et al., 2015) and the brain-derived neurotrophic factor (BDNF) receptor, TrkB (Tong et al., 2004; Echeverria et al., 2007). Additionally, $\mathrm{A} \beta \mathrm{O}$ s activate microglia, triggering exacerbated release of proinflammatory cytokines implicated in memory impairment and mood alterations in mouse models of $\mathrm{AD}$ (Ledo et al., 2013, 2016).

PTP1B emerged recently as a regulator of a variety of processes within the central nervous system (CNS), many of which therapeutically relevant for AD. Increased PTP1B activity is associated with defective neuronal insulin and leptin signaling (Zabolotny et al., 2002; Pandey et al., 2013, 2014), pathways that are impaired in AD (Bomfim et al., 2012; Bonda et al., 2014). Significantly, down-regulation of PTP1B restores hypothalamic insulin and leptin signaling (ChiarreottoRopelle et al., 2013; Lindtner et al., 2013; Pandey et al., 2013, 2014; Yu et al., 2013). PTP1B down-regulates neuronal BDNF-TrkB pathway, whereas PTP1B inhibition boosts BDNF signaling (Ozek et al., 2014; Krishnan et al., 2015). Importantly, mice lacking PTP1B in the hippocampus and cortex displayed improved performance in the Barnes maze (Fuentes et al., 2012), posing this phosphatase as a negative regulator of spatial memory. PTP1B negatively regulates hippocampal storeoperated calcium entry (nSOC; Koss et al., 2013), an essential process for the stabilization of mushroom spines that is impaired in transgenic AD mice (Sun et al., 2014; Zhang H. et al., 2015). Furthermore, PTP1B is up-regulated by endoplasmic reticulum (ER) stress (Agouni et al., 2011; Popov, 2012; Hakim et al., 2015), a neuronal response activated by $A \beta O$ s and implicated in synapse loss and cognitive decline in AD (Kam et al., 2013; Lourenco et al., 2013). Finally, PTP1B is highly expressed in hippocampal microglia (Pei et al., 1994), and was recently described as a positive regulator of neuroinflammation (Song et al., 2016).

In the following sections, we review evidence suggesting that PTP1B modulates several CNS processes relevant to the physiopathology of $\mathrm{AD}$, making it an attractive target to be explored in $\mathrm{AD}$ pharmacotherapy. Inhibiting PTP1B appears as a promising, yet neglected strategy to combat multiple aspects of $\mathrm{AD}$.

\section{INSULIN SIGNALING}

Insulin signaling is initiated by activation of IR autophosphorylation at tyrosine residues upon insulin binding (Guo, 2014). The immediate effectors IRS-1 and IRS-2 (IR substrate 1 and 2) are then recruited and activated by tyrosine phosphorylation to propagate intracellular signaling (Guo, 2014). PTP1B dephosphorylates tyrosine residues in IR and IRS-1 (Figure 1), reducing insulin sensitivity and shutting down signaling (Goldstein et al., 2000; Bakke and Haj, 2015). PTP1B deficient mice are hypersensitive to insulin and present low basal glycemia and insulinemia (Elchebly et al., 1999), and inhibiting PTP1B improves insulin signaling and reverses T2D phenotypes (Malamas et al., 2000; Zinker et al., 2002; Gum et al., 2003; Tamrakar et al., 2014). Conversely, exacerbated PTP1B activity underlies insulin resistance in T2D (Zabolotny et al., 2002; González-Rodríguez et al., 2010).

An epidemiological correlation between AD and T2D exists, with each disease increasing the risk of developing the other (Ott et al., 1996; Craft and Watson, 2004; De Felice, 2013a,b). However, the mechanisms underlying this connection remain elusive. A breakthrough discovery that contributed to current understanding of such mechanisms was that neurons exposed to $\mathrm{A} \beta \mathrm{O}$ s become insensitive to insulin (Zhao et al., 2008; De Felice et al., 2009). Further studies showed that A $\beta O$ s impair insulin signaling by increasing IRS-1 inhibitory serine phosphorylation and decreasing activating tyrosine phosphorylation (Bomfim et al., 2012). Importantly, defective insulin signaling was confirmed in post mortem AD brains (Bomfim et al., 2012; Talbot et al., 2012). Conversely, boosting insulin signaling protects synapses against A $\beta$ Os toxicity (De Felice et al., 2009). These discoveries paved the way for a whole new aspect of $\mathrm{AD}$, which has provided important advances of therapeutic relevance. For instance, anti-diabetic drugs developed to treat insulin resistance in $\mathrm{T} 2 \mathrm{D}$ have shown promising preclinical results, protecting synapses, preventing inhibition of IRS-1 and, most importantly, ameliorating cognitive phenotypes in animal models of AD (McClean et al., 2011; Bomfim et al., 2012; Hansen et al., 2015; Qi et al., 2016). Those studies have provided molecular grounds for on-going clinical trials aimed at testing the efficacy of intranasal insulin and glucagon-like peptide 1 (GLP-1) analogs in $\mathrm{AD}$ (De Felice and Ferreira, 2014).

Thus, it seems reasonable to predict that PTP1B inhibitors-which restore insulin sensitivity in T2D models (Malamas et al., 2000; Zinker et al., 2002; Gum et al., 2003; Panzhinskiy et al., 2013; Tamrakar et al., 2014)-may rescue neurons from defective insulin signaling in AD. Although this hypothesis has not yet been tested directly, there is evidence from non-AD models of neuronal insulin resistance validating PTP1B inhibition as an effective approach to rescue neuronal insulin signaling (Krishnan et al., 2015; Qin et al., 2015a; Zhang Z. Y. et al., 2015).

\section{LEPTIN SIGNALING}

In obesity, defective hypothalamic leptin signaling impairs sensing and processing of satiety signals, leading to increased caloric intake and decreased energy expenditure (Halaas et al., 1995; Farooqi et al., 1999; Morton et al., 2006). Ob/Ob mice, which do not produce leptin, exhibit increased food intake and become profoundly obese (Zhang et al., 1994). Leptin signaling is initiated by binding of leptin to LepR, leading to tyrosine autophosphorylation of LepR and subsequent phosphorylation of Janus kinase 2 (JAK2), which propagates downstream intracellular signaling (Iida et al., 1996; Fei et al., 1997). 


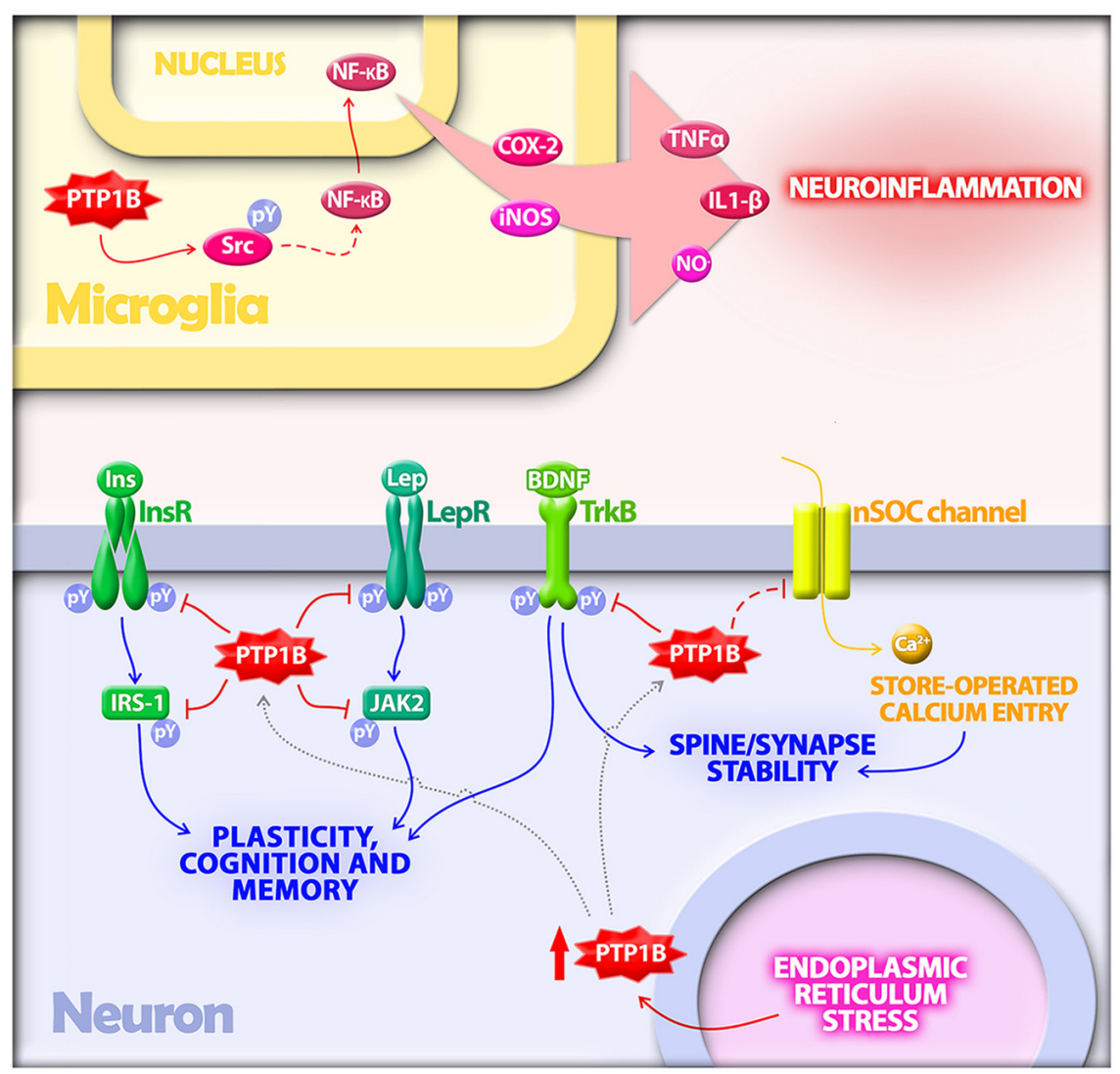

FIGURE 1 | Protein tyrosine phosphatase 1B (PTP1B) regulates multiple mechanisms implicated in the pathogenesis of Alzheimer's disease (AD). In microglia, PTP1B is a positive regulator of neuroinflammation. PTP1B activates Src via dephosphorylation at a negative regulatory site. Src, in turn, indirectly activates NF-kB, a transcriptional regulator of proinflammatory mediators including TNF- $\alpha$, IL-1 $\beta$, COX-2 and inducible nitric oxide synthase (iNOS). In neurons, PTP1B is upregulated by endoplasmic reticulum (ER) stress, a cellular response activated by amyloid- $\beta$ oligomers (A $30 s$ ) in AD. Elevated PTP1B inhibits signaling by receptor tyrosine kinases germane to synaptic plasticity, cognition and memory. Substrates for PTP1B in neurons that have been implicated in AD include the insulin receptor (InsR) and its substrate IRS-1, the leptin receptor (LepR) and its immediate downstream effector Janus kinase 2 (JAK2), and the brain-derived neurotrophic factor (BDNF) receptor (TrkB). PTP1B further regulates neuronal store-operated calcium entry (nSOC), a mechanism required for spine/synaptic stability found to be impaired in models of AD.

Strong evidence implicates PTP1B in obesity-associated hypothalamic leptin resistance (Cheng et al., 2002; Zabolotny et al., 2002). PTP1B dephosphorylates LepR and JAK2, functioning as a negative regulator of leptin signaling (Figure 1). PTP1B-null mice are resistant to weight gain induced by high-fat diet (HFD) or by deletion of the leptin gene, suggesting PTP1B inhibition as a strategy to rescue leptin signaling in food intake disorders and obesity (Elchebly et al., 1999; Cheng et al., 2002).

Beyond hypothalamic signaling, leptin plays important roles in the CNS. LepRs are highly expressed in the hippocampus (Huang et al., 1996; Mercer et al., 1996; Scott et al., 2009) where leptin signaling is important for cognition and memory (Irving and Harvey, 2014). A $\beta$ down-regulates hippocampal leptin and LepR expression (Marwarha et al., 2010; Bonda et al., 2014). Interestingly, leptin prevents hippocampal synaptic disruption and neuronal death induced by $\mathrm{A} \beta$ (Doherty et al., 2013). Leptin also modifies $\mathrm{A} \beta$ levels (Fewlass et al., 2004) and reduces tau phosphorylation in neuronal cells (Greco et al., 2008, 2009a,b).
Importantly, neuronal leptin resistance has been described in the AD hippocampus (Bonda et al., 2014; Maioli et al., 2015), further underlining the relevance of defective leptin signaling in $\mathrm{AD}$.

Leptin signaling has been proposed as a neuroprotective target in $\mathrm{AD}$ (Gomes et al., 2014; Johnston et al., 2014). Because direct administration of leptin or LepR agonists in conditions of leptin resistance may not result in the desired biological effect, a more attractive approach to boost leptin signaling in $\mathrm{AD}$ would be to reverse neuronal leptin resistance. The evidence described above suggests that recovery of leptin sensitivity could be achieved by PTP1B inhibitors.

\section{ENDOPLASMIC RETICULUM STRESS}

ER stress and activation of the unfolded protein response (UPR) are important toxic mechanisms in AD (Lourenco et al., 2015). We recently demonstrated that $A \beta O$ s trigger ER stress in hippocampal neurons in a mechanism that requires TNF- 
$\alpha$ receptor activation (Lourenco et al., 2013). ER stress triggered by TNF- $\alpha$ has also been linked to peripheral insulin resistance in obesity and diabetes (reviewed in Hotamisligil, 2010).

PTP1B localizes predominantly to the cytoplasmic surface of the ER (Haj et al., 2002) and mediates ER stress signaling (Wang et al., 2009). Downregulation of PTP1B ameliorates ER stress in obesity and diabetes models (Delibegovic et al., 2009; Agouni et al., 2011; Owen et al., 2013). Two of the UPR branches activated upon ER stress involve inositolrequiring enzyme 1 (IRE-1) and activating transcription factor 6 (ATF6). Interestingly, PTP1B potentiates IRE-1-mediated ER stress response and its expression is regulated by ATF6 (Gu et al., 2004; Wang et al., 2009). Moreover, recent evidence links hypothalamic ER stress and activation of the UPR to development of PTP1B-mediated leptin resistance and increased food intake following chronic sleep fragmentation in mice (Hakim et al., 2015).

Collectively, data suggest that PTP1B mediates the toxic consequences of neuronal ER stress (Figure 1). It has been hypothesized that PTP1B may be a key link between insulin signaling and ER stress (Popov, 2012). This raises the possibility that PTP1B inhibitors may be able to compensate the detrimental impact of ER stress on synapse stability and cognition in AD.

\section{SYNAPTIC PLASTICITY, STABILITY AND MEMORY}

The functions of PTP1B in neurophysiology are gaining traction as novel roles for PTP1B in the brain are discovered. PTP1B has been implicated in a variety of neuronal processes, including some related to synapse biology that are potentially relevant to the pathogenesis of $\mathrm{AD}$.

$\mathrm{BDNF}$ is a major regulator of synaptic plasticity. BDNF signaling through its receptor, $\operatorname{TrkB}$, modulates synapse structure and function to produce long-term potentiation (LTP), a form of activity-dependent synaptic plasticity thought to underlie learning and memory (Leal et al., 2015). AD brains display reduced BDNF levels in clinical (Phillips et al., 1991; Connor et al., 1997; Soontornniyomkij et al., 1999) and preclinical disease stages (Peng et al., 2005). Conversely, BDNF is neuroprotective in animal models of AD (Arancibia et al., 2008; Nagahara et al., 2009). Therefore, stimulating BDNF signaling represents an attractive approach in $\mathrm{AD}$ therapy.

Recent studies showed that PTP1B downregulates BDNF signaling through dephosphorylation of TrkB (Ozek et al., 2014; Krishnan et al., 2015; Figure 1). Ptpn $1^{-/-}$mice are hypersensitive to BDNF, and pharmacological inhibition of PTP1B increases neuronal responsiveness BDNF (Ozek et al., 2014). PTP1B inhibition may, thus, represent a means to enhance BDNF signaling, improving synaptic plasticity and cognition in AD.

PTP1B has further been implicated in hippocampal synapse formation and learning (Fuentes et al., 2012). PTP1B is present in dendritic spines of hippocampal neurons, and functional or genetic PTP1B deficiency affects spine morphology and leads to disorganization of pre- and post-synaptic terminals.
Interestingly, mice lacking $\mathrm{PTP} 1 \mathrm{~B}$ in the hippocampus and cortex exhibit improved performance in the Barnes maze compared to wild-type controls, posing this phosphatase as a negative regulator of spatial memory (Fuentes et al., 2012).

Neuronal store-operated calcium entry (nSOC) is essential for stabilization of mushroom spines in hippocampal neurons (Sun et al., 2014). AD mice exhibit impaired nSOC, which causes destabilization and loss of spines through a mechanism involving overactivation of metabotropic glutamate receptor 5 (mGluR5; Sun et al., 2014; Zhang H. et al., 2015). PTP1B is a negative regulator of hippocampal nSOC (Koss et al., 2013; Figure 1), suggesting PTP1B inhibition may restore deficient nSOC.

Collectively, these findings suggest PTP1B inhibition may result in improved synapse plasticity, function and stability, ultimately enhancing cognitive performance.

\section{MICROGLIA-MEDIATED NEUROINFLAMMATION}

Chronic neuroinflammation is an important feature of $\mathrm{AD}$ (Heneka et al., 2015; Heppner et al., 2015). Evidence for activated microglia has been described in transgenic AD mice (Frautschy et al., 1998; Bornemann et al., 2001) and in AD brains (Cagnin et al., 2001; Edison et al., 2008). Microglia are implicated in cognitive impairment in $\mathrm{AD}$ through sustained secretion of neurotoxic cytokines (Wang et al., 2015) and synapse pruning (Hong et al., 2016; Lui et al., 2016). Injection of AßOs in mouse brains induces microglia-mediated neuroinflammation (Xu et al., 2016), leading to memory impairment and mood alterations (Ledo et al., 2013, 2016). Direct activation of microglia by A $\beta O s$ was recently demonstrated in primary microglial cultures (Ledo et al., 2016).

Activated microglia are the main source of proinflammatory cytokines such as TNF- $\alpha$ and IL- $1 \beta$ in the brain (Wang et al., 2015). TNF- $\alpha$ is implicated in memory impairment caused by A $\beta$ Os (Bomfim et al., 2012; Lourenco et al., 2013). Activation of TNF- $\alpha$ signaling is associated with inhibition of IRS-1 in hippocampal neurons (Bomfim et al., 2012). TNF- $\alpha$ is also implicated in peripheral insulin resistance in diabetes (Hotamisligil et al., 1993; Hotamisligil and Spiegelman, 1994), and it has been proposed that neuronal insulin resistance induced by TNF- $\alpha$ may underlie the connection between diabetes and AD (De Felice and Ferreira, 2014). IL-1 $\beta$ has been described as a mediator of cognitive impairment associated with peripheral and central inflammation by disrupting hippocampal synaptic plasticity (Di Filippo et al., 2013; Erion et al., 2014). These lines of evidence support dampening microglia-mediated neuroinflammation as an attractive therapeutic approach in AD (Ransohoff, 2016; Santos et al., 2016; Wes et al., 2016).

PTP1B is regulated by proinflammatory signals and is highly expressed in hippocampal microglia in AD (Pei et al., 1994). Interestingly, a recent study unraveled a novel role for PTP1B as a positive regulator of neuroinflammation (Song et al., 2016). PTP1B levels are increased in LPS injected brain, and PTP1B overexpression potentiates microglial responses via dephosphorylation/activation of Src and nuclear 
translocation of NF- $\mathrm{B}$, leading to increased expression of proinflammatory molecules including TNF- $\alpha$, IL- $1 \beta$, cyclooxigenase- 2 and inducible nitric oxide synthase (iNOS; Figure 1). Significantly, LPS-induced neuroinflammation is attenuated by pharmacological PTP1B inhibitors (Song et al., 2016). Conversely, TNF- $\alpha$ increases PTP1B expression via NFкB in adipose tissue of HFD mice (Zabolotny et al., 2008) and in organotypic hypothalamic cultures (Ito et al., 2012), further exacerbating inflammation in a feed-forward mechanism. This suggests that pharmacological inhibition of PTP1B may constitute a therapeutic strategy to counteract neuroinflammation.

\section{PTP1B INHIBITORS AS DRUG CANDIDATES FOR NEUROLOGICAL DISEASES}

PTP1B has long been pursued as a therapeutic target in human diseases, particularly in diabetes and obesity (Zhang and Lee, 2003). Multiple PTP1B inhibitors have been developed and tested in preclinical models, validating the concept of PTP1B inhibition as an effective therapeutic approach for diabetes (Tamrakar et al., 2014). Nevertheless, certain structural features of PTP1B complicate the development of small molecule inhibitors with fundamental characteristics required for drug candidates, namely, specificity/selectivity and bioavailabilty. First, the active sites of protein tyrosine phosphatases (PTPs) are highly conserved among the more than 100 family members (Tonks, 2013). Therefore, inhibitors designed to bind to the active site of PTP1B often inhibit other PTPs as well, leading to off-target effects (Tamrakar et al., 2014; Tautz, 2015). Second, most inhibitors developed so far are phosphotyrosine-mimicking molecules bearing a charged group, which drastically affects pharmacokinetics (Tautz, 2015). For those reasons, few PTP1B inhibitors have reached clinical trials, and none have made it through phase II tests (Tamrakar et al., 2014; Tautz, 2015).

In $\mathrm{AD}$, the blood-brain barrier $(\mathrm{BBB})$ represents an additional obstacle drugs need to overcome to reach the CNS. Fortunately, however, significant advances have been achieved in developing effective PTP1B inhibitors with potential for clinical use. For example, an important recent study provided compelling evidence that potent and selective PTP1B inhibitors administered peripherally (e.g., intraperitoneally or subcutaneously) inhibit PTP1B activity in the brain (Krishnan et al., 2015). MeCP2 deficient mice, a model of Rett syndrome, exhibit increased PTP1B expression, leading to defective brain insulin signaling and impaired glucose metabolism. This was associated with neurological phenotypes in female mice and reduced lifespan in male mice, recapitulating Rett syndrome in humans. Remarkably, long-term systemic treatment with two distinct PTP1B inhibitors, CPT157633 and UA0713, rescued disease phenotypes in $\mathrm{MeCP} 2$ deficient mice. Moreover, PTP1B inhibitors increased tyrosine phosphorylation of TrkB, leading to enhanced signaling in response to BDNF in the forebrains of MeCP2 deficient mice (Krishnan et al., 2015).

Another recent study showed that intraperitoneal administration of trodusquemine, a selective BBB-permeant
(Ahima et al., 2002; Lantz et al., 2010) PTP1B inhibitor, relieved anxiety in $\mathrm{LMO} 4$ knockout mice exhibiting impaired endocannabinoid signaling due to increased PTP1B activity in amygdala (Qin et al., 2015b). Those studies support the feasibility of using peripherally administered PTP1B inhibitors to treat CNS disorders.

\section{CONCLUSION}

Compelling recent findings suggest PTP1B holds potential as a therapeutic target in $\mathrm{AD}$. Results indicate that PTP1B regulates distinct $\mathrm{CNS}$ responses depending on cell type: while PTP1B modulates insulin and leptin signaling in neurons, it regulates astrocyte differentiation (Yamada et al., 2013) and proinflammatory responses in microglia. Because PTP1B participates in several cellular/molecular processes linked to $\mathrm{AD}$ pathogenesis (Figure 1), compounds capable of reaching the CNS and inhibiting PTP1B activity in neurons and/or glial cells may rescue multiple aberrant processes associated with cognitive decline and neurodegeneration in AD.

Detailed preclinical studies are warranted to validate the potential benefits of PTP1B inhibition in AD models. Because PTP1B may interfere with pathological mechanisms that operate at different disease stages, it will be important to investigate whether PTP1B inhibition delays, prevents or slows down disease progression or temporarily ameliorates symptoms.

Finally, the above described pathological mechanisms in which PTP1B has been implicated are not exclusively associated with $\mathrm{AD}$, but also with other neurological disorders. This raises the possibility that PTP1B inhibition may be useful for treatment of other brain disorders related to metabolic deregulation, and perhaps even in normal, age-related cognitive decline.

\section{AUTHOR CONTRIBUTIONS}

MNNV: development of the subject matter, drafting of the article, conception and design of the figure, critical revision of the article, final approval of the version to be published; NMLS and FGF: development of the subject matter, drafting of the article, critical revision of the article, final approval of the version to be published; STF: discussion of contents, critical revision of the article, final approval of the version to be published.

\section{FUNDING}

Work in the authors' laboratory is funded by grants from Conselho Nacional de Desenvolvimento Científico e Tecnológico (CNPq), Fundação de Amparo à Pesquisa do Estado do Rio de Janeiro (FAPERJ), National Institute for Translational Neuroscience (to FGF and STF) and Canadian Institutes of Health Research (CIHR; to FGF). MNNV is a former postdoctoral fellow of $\mathrm{CNPq}$ and a current fellow of FAPERJ. Studies on PTP1B inhibition as a therapy to Alzheimer's disesase are funded by the International Society for Neurochemistry (ISN) Committee for Aid and Education in Neurosciences (CAEN) Career Interruption, Re-entry Grant (to MNNV). NMLS is a pre-doctoral fellow of CNPq. 


\section{REFERENCES}

Agouni, A., Mody, N., Owen, C., Czopek, A., Zimmer, D., Bentires-Alj, M., et al. (2011). Liver-specific deletion of protein tyrosine phosphatase (PTP) 1B improves obesity- and pharmacologically induced endoplasmic reticulum stress. Biochem. J. 438, 369-378. doi: 10.1042/BJ20110373

Ahima, R. S., Patel, H. R., Takahashi, N., Qi, Y., Hileman, S. M., and Zasloff, M. A. (2002). Appetite suppression and weight reduction by a centrally active aminosterol. Diabetes 51, 2099-2104. doi: 10.2337/diabetes.51.7.2099

Arancibia, S., Silhol, M., Moulière, F., Meffre, J., Höllinger, I., Maurice, T., et al. (2008). Protective effect of BDNF against beta-amyloid induced neurotoxicity in vitro and in vivo in rats. Neurobiol. Dis. 31, 316-326. doi: 10.1016/j.nbd.2008. 05.012

Bakke, J., and Haj, F. G. (2015). Protein-tyrosine phosphatase 1B substrates and metabolic regulation. Semin. Cell Dev. Biol. 37, 58-65. doi: 10.1016/j.semcdb. 2014.09.020

Bomfim, T. R., Forny-Germano, L., Sathler, L. B., Brito-Moreira, J., Houzel, J. C., Decker, H., et al. (2012). An anti-diabetes agent protects the mouse brain from defective insulin signaling caused by Alzheimer's disease- associated A $\beta$ oligomers. J. Clin. Invest. 122, 1339-1353. doi: 10.1172/jci57256

Bonda, D. J., Stone, J. G., Torres, S. L., Siedlak, S. L., Perry, G., Kryscio, R., et al. (2014). Dysregulation of leptin signaling in Alzheimer disease: evidence for neuronal leptin resistance. J. Neurochem. 128, 162-172. doi: 10.1111/jnc. 12380

Bornemann, K. D., Wiederhold, K.-H., Pauli, C., Ermini, F., Stalder, M., Schnell, L., et al. (2001). A $\beta$-induced inflammatory processes in microglia cells of APP23 transgenic mice. Am. J. Pathol. 158, 63-73. doi: 10.1016/s00029440(10)63945-4

Cagnin, A., Brooks, D. J., Kennedy, A. M., Gunn, R. N., Myers, R., Turkheimer, F. E., et al. (2001). In vivo measurement of activated microglia in dementia. Lancet 358, 461-467. doi: 10.1016/s0140-6736(01)05625-2

Cheng, A., Uetani, N., Simoncic, P. D., Chaubey, V. P., Lee-Loy, A., McGlade, C. J., et al. (2002). Attenuation of leptin action and regulation of obesity by protein tyrosine phosphatase 1B. Dev. Cell 2, 497-503. doi: 10.1016/s15345807(02)00149-1

Chiarreotto-Ropelle, E. C., Pauli, L. S., Katashima, C. K., Pimentel, G. D., Picardi, P. K., Silva, V. R., et al. (2013). Acute exercise suppresses hypothalamic PTP1B protein level and improves insulin and leptin signaling in obese rats. Am. J. Physiol. Endocrinol. Metab. 305, E649-E659. doi: 10.1152/ajpendo. 00272.2013

Connor, B., Young, D., Yan, Q., Faull, R. L., Synek, B., and Dragunow, M. (1997). Brain-derived neurotrophic factor is reduced in Alzheimer's disease. Mol. Brain Res. 49, 71-81. doi: 10.1016/s0169-328x(97)00125-3

Craft, S., and Watson, G. S. (2004). Insulin and neurodegenerative disease: shared and specific mechanisms. Lancet Neurol. 3, 169-178. doi: 10.1016/s14744422(04)00681-7

Delibegovic, M., Zimmer, D., Kauffman, C., Rak, K., Hong, E. G., Cho, Y. R., et al. (2009). Liver-specific deletion of protein-tyrosine phosphatase 1B (PTP1B) improves metabolic syndrome and attenuates diet-induced endoplasmic reticulum stress. Diabetes 58, 590-599. doi: 10.2337/db08-0913

Doherty, G. H., Beccano-Kelly, D., Yan, S. D., Gunn-Moore, F. J., and Harvey, J. (2013). Leptin prevents hippocampal synaptic disruption and neuronal cell death induced by amyloid $\beta$. Neurobiol. Aging 34, 226-237. doi: 10.1016/j. neurobiolaging.2012.08.003

Echeverria, V., Berman, D. E., and Arancio, O. (2007). Oligomers of $\beta$-amyloid peptide inhibit BDNF-induced arc expression in cultured cortical neurons. Curr. Alzheimer Res. 4, 518-521. doi: 10.2174/156720507783018190

Edison, P., Archer, H. A., Gerhard, A., Hinz, R., Pavese, N., Turkheimer, F. E., et al. (2008). Microglia, amyloid, and cognition in Alzheimer's disease: an [11C](R)PK11195-PET and [11C]PIB-PET study. Neurobiol. Dis. 32, 412-419. doi: 10.1016/j.nbd.2008.08.001

Elchebly, M., Payette, P., Michaliszyn, E., Cromlish, W., Collins, S., Loy, A. L., et al. (1999). Increased insulin sensitivity and obesity resistance in mice lacking the protein tyrosine phosphatase-1B gene. Science 283, 1544-1548. doi: 10.1126/science.283.5407.1544

Erion, J. R., Wosiski-Kuhn, M., Dey, A., Hao, S., Davis, C. L., Pollock, N. K., et al. (2014). Obesity elicits interleukin 1-mediated deficits in hippocampal synaptic plasticity. J. Neurosci. 34, 2618-2631. doi: 10.1523/JNEUROSCI.4200-13.2014
Farooqi, I. S., Jebb, S. A., Langmack, G., Lawrence, E., Cheetham, C. H., Prentice, A. M., et al. (1999). Effects of recombinant leptin therapy in a child with congenital leptin deficiency. N. Engl. J. Med. 341, 879-884. doi: 10.1056/NEJM199909163411204

Fei, H., Okano, H. J., Li, C., Lee, G.-H., Zhao, C., Darnell, R., et al. (1997). Anatomic localization of alternatively spliced leptin receptors (Ob-R) in mouse brain and other tissues. Proc. Natl. Acad. Sci. U S A 94, 7001-7005. doi: 10.1073/pnas.94.13.7001

De Felice, F. G. (2013a). Alzheimer's disease and insulin resistance: translating basic science into clinical applications. J. Clin. Invest. 123, 531-539. doi: 10.1172/JCI64595

De Felice, F. G. (2013b). Connecting type 2 diabetes to Alzheimer's disease. Expert Rev. Neurother. 13, 1297-1299. doi: 10.1586/14737175.2013.864824

Di Filippo, M., Chiasserini, D., Gardoni, F., Viviani, B., Tozzi, A., Giampà, C., et al. (2013). Effects of central and peripheral inflammation on hippocampal synaptic plasticity. Neurobiol. Dis. 52, 229-236. doi: 10.1016/j.nbd.2012.12.009

De Felice, F. G., and Ferreira, S. T. (2014). Inflammation, defective insulin signaling and mitochondrial dysfunction as common molecular denominators connecting type 2 diabetes to Alzheimer disease. Diabetes 63, 2262-2272. doi: $10.2337 / \mathrm{db} 13-1954$

De Felice, F. G., Vieira, M. N. N., Bomfim, T. R., Decker, H., Velasco, P. T. Lambert, M. P., et al. (2009). Protection of synapses against Alzheimer'slinked toxins: insulin signaling prevents the pathogenic binding of $\mathrm{A} \beta$ oligomers. Proc. Natl. Acad. Sci. U S A 106, 1971-1976. doi: 10.1073/pnas.08091 58106

Ferreira, S. T., and Klein, W. L. (2011). The A $\beta$ oligomer hypothesis for synapse failure and memory loss in Alzheimer's disease. Neurobiol. Learn. Mem. 96, 529-543. doi: 10.1016/j.nlm.2011.08.003

Ferreira, S. T., Lourenco, M. V., Oliveira, M. M., and De Felice, F. G. (2015). Soluble amyloid- $\beta$ oligomers as synaptotoxins leading to cognitive impairment in Alzheimer's disease. Front. Cell. Neurosci. 9:191. doi: 10.3389/fncel.2015. 00191

Fewlass, D. C., Noboa, K., Pi-Sunyer, F. X., Johnston, J. M., Yan, S. D., and Tezapsidis, N. (2004). Obesity-related leptin regulates Alzheimer's A $\beta$. FASEB J. 18, 1870-1878. doi: 10.1096/fj.04-2572com

Frautschy, S. A., Yang, F., Irrizarry, M., Hyman, B., Saido, T. C., Hsiao, K., et al. (1998). Microglial response to amyloid plaques in APPsw transgenic mice. Am. J. Pathol. 152, 307-317.

Fuentes, F., Zimmer, D., Atienza, M., Schottenfeld, J., Penkala, I., Bale, T., et al. (2012). Protein tyrosine phosphatase PTP1B is involved in hippocampal synapse formation and learning. PLoS One 7:e41536. doi: 10.1371/journal.pone. 0041536

Goldstein, B. J., Bittner-Kowalczyk, A., White, M. F., and Harbeck, M. (2000). Tyrosine dephosphorylation and deactivation of insulin receptor substrate-1 by protein-tyrosine phosphatase $1 \mathrm{~B}$. Possible facilitation by the formation of a ternary complex with the Grb2 adaptor protein. J. Biol. Chem. 275, 4283-4289. doi: $10.1074 /$ jbc. 275.6 .4283

Gomes, S., Martins, I., Fonseca, A. C., Oliveira, C. R., Resende, R., and Pereira, C. M. (2014). Protective effect of leptin and ghrelin against toxicity induced by amyloid- $\beta$ oligomers in a hypothalamic cell line. J. Neuroendocrinol. 26, 176-185. doi: 10.1111/jne.12138

González-Rodríguez, Á., Mas Gutierrez, J. A., Sanz-González, S., Ros, M., Burks, D. J., and Valverde, Á. M. (2010). Inhibition of PTP1B restores IRS1-mediated hepatic insulin signaling in IRS2-deficient mice. Diabetes 59, 588-599. doi: 10.2337/db09-0796

Greco, S. J., Sarkar, S., Casadesus, G., Zhu, X., Smith, M. A., Ashford, J. W., et al. (2009a). Leptin inhibits glycogen synthase kinase-3 $\beta$ to prevent tau phosphorylation in neuronal cells. Neurosci. Lett. 455, 191-194. doi: 10.1016/j. neulet.2009.03.066

Greco, S. J., Sarkar, S., Johnston, J. M., and Tezapsidis, N. (2009b). Leptin regulates tau phosphorylation and amyloid through AMPK in neuronal cells. Biochem. Biophys. Res. Commun. 380, 98-104. doi: 10.1016/j.bbrc.2009.01.041

Greco, S. J., Sarkar, S., Johnston, J. M., Zhu, X., Su, B., Casadesus, G., et al. (2008). Leptin reduces Alzheimer's disease-related tau phosphorylation in neuronal cells. Biochem. Biophys. Res. Commun. 376, 536-541. doi: 10.1016/j.bbrc.2008. 09.026

Gu, F., Nguyên, D. T., Stuible, M., Dubé, N., Tremblay, M. L., and Chevet, E. (2004). Protein-tyrosine phosphatase 1B potentiates IRE1 signaling 
during endoplasmic reticulum stress. J. Biol. Chem. 279, 49689-49693. doi: $10.1074 /$ jbc.c400261200

Gum, R. J., Gaede, L. L., Koterski, S. L., Heindel, M., Clampit, J. E., Zinker, B. A., et al. (2003). Reduction of protein tyrosine phosphatase 1B increases insulindependent signaling in ob/ob mice. Diabetes 52, 21-28. doi: 10.2337/diabetes. 52.1.21

Guo, S. (2014). Insulin signaling, resistance and the metabolic syndrome: insights from mouse models into disease mechanisms. J. Endocrinol. 220, T1-T23. doi: 10.1530/JOE-13-0327

Haj, F. G., Verveer, P. J., Squire, A., Neel, B. G., and Bastiaens, P. I. (2002). Imaging sites of receptor dephosphorylation by PTP1B on the surface of the endoplasmic reticulum. Science 295, 1708-1711. doi: 10.1126/science.10 67566

Hakim, F., Wang, Y., Carreras, A., Hirotsu, C., Zhang, J., Peris, E., et al. (2015). Chronic sleep fragmentation during the sleep period induces hypothalamic endoplasmic reticulum stress and PTP1b-mediated leptin resistance in male mice. Sleep 38, 31-40. doi: 10.5665/sleep.4320

Halaas, J. L., Gajiwala, K. S., Maffei, M., Cohen, S. L., Chait, B. T., Rabinowitz, D., et al. (1995). Weight-reducing effects of the plasma protein encoded by the obese gene. Science 269, 543-546. doi: 10.1126/science.7624777

Hansen, T. H., Vestergaard, H., Jørgensen, T., Jørgensen, M. E., Lauritzen, T., Brandslund, I., et al. (2015). Impact of PTBP1 rs11085226 on glucosestimulated insulin release in adult Danes. BMC Med. Genet. 16:17. doi: 10.1186/s12881-015-0160-7

Heneka, M. T., Carson, M. J., El Khoury, J., Landreth, G. E., Brosseron, F., Feinstein, D. L., et al. (2015). Neuroinflammation in Alzheimer's disease. Lancet Neurol. 14, 388-405. doi: 10.1016/S1474-4422(15)70016-5

Heppner, F. L., Ransohoff, R. M., and Becher, B. (2015). Immune attack: the role of inflammation in Alzheimer disease. Nat. Rev. Neurosci. 16, 358-372. doi: $10.1038 / \mathrm{nrn} 3880$

Hong, S., Beja-Glasser, V. F., Nfonoyim, B. M., Frouin, A., Li, S., Ramakrishnan, S., et al. (2016). Complement and microglia mediate early synapse loss in Alzheimer mouse models. Science 352, 712-716. doi: 10.1126/science. aad 8373

Hotamisligil, G. S. (2010). Endoplasmic reticulum stress and the inflammatory basis of metabolic disease. Cell 140, 900-917. doi: 10.1016/j.cell.2010. 02.034

Hotamisligil, G. S., Shargill, N. S., and Spiegelman, B. M. (1993). Adipose expression of tumor necrosis factor-alpha: direct role in obesity-linked insulin resistance. Science 259, 87-91. doi: 10.1126/science.7678183

Hotamisligil, G. S., and Spiegelman, B. M. (1994). Tumor necrosis factor $\alpha$ : a key component of the obesity-diabetes link. Diabetes 43, 1271-1278. doi: 10.2337/diabetes.43.11.1271

Huang, X. F., Koutcherov, I., Lin, S., Wang, H. Q., and Storlien, L. (1996). Localization of leptin receptor mRNA expression in mouse brain. Neuroreport 7, 2635-2638. doi: 10.1097/00001756-199611040-00045

Iida, M., Murakami, T., Ishida, K., Mizuno, A., Kuwajima, M., and Shima, K. (1996). Phenotype-linked amino acid alteration in leptin receptor cDNA from Zucker fatty (fa/fa) rat. Biochem. Biophys. Res. Commun. 222, 19-26. doi: 10.1006/bbrc. 1996.0691

Irving, A. J., and Harvey, J. (2014). Leptin regulation of hippocampal synaptic function in health and disease. Philos. Trans. R. Soc. Lond. B Biol. Sci. 369:20130155. doi: 10.1098/rstb.2013.0155

Ito, Y., Banno, R., Hagimoto, S., Ozawa, Y., Arima, H., and Oiso, Y. (2012). TNF $\alpha$ increases hypothalamic PTP1B activity via the NFkappaB pathway in rat hypothalamic organotypic cultures. Regul. Pept. 174, 58-64. doi: 10.1016/j. regpep.2011.11.010

Johnston, J. M., Hu, W. T., Fardo, D. W., Greco, S. J., Perry, G., Montine, T. J., et al. (2014). Low plasma leptin in cognitively impaired ADNI subjects: gender differences and diagnostic and therapeutic potential. Curr. Alzheimer Res. 11, 165-174. doi: 10.2174/1567205010666131212114156

Jürgensen, S., Antonio, L. L., Mussi, G. E. A., Brito-Moreira, J., Bomfim, T. R., De Felice, F. G., et al. (2011). Activation of D1/D5 dopamine receptors protects neurons from synapse dysfunction induced by amyloid- $\beta$ oligomers. J. Biol. Chem. 286, 3270-3276. doi: 10.1074/jbc.M110.177790

Kam, T.-I., Song, S., Gwon, Y., Park, H., Yan, J.-J., Im, I., et al. (2013). FcyRIIb mediates amyloid- $\beta$ neurotoxicity and memory impairment in Alzheimer's disease. J. Clin. Invest. 123, 2791-2802. doi: 10.1172/JCI66827
Koss, D. J., Riedel, G., Bence, K., and Platt, B. (2013). Store-operated $\mathrm{Ca}^{2+}$ entry in hippocampal neurons: regulation by protein tyrosine phosphatase PTP1B. Cell Calcium 53, 125-138. doi: 10.1016/j.ceca.2012.11.004

Krishnan, N., Krishnan, K., Connors, C. R., Choy, M. S., Page, R., Peti, W., et al. (2015). PTP1B inhibition suggests a therapeutic strategy for Rett syndrome. J. Clin. Invest. 125, 3163-3177. doi: 10.1172/JCI80323

Lacor, P. N., Buniel, M. C., Chang, L., Fernandez, S. J., Gong, Y., Viola, K. L., et al. (2004). Synaptic targeting by Alzheimer's-related amyloid $\beta$ oligomers. J. Neurosci. 24, 10191-10200. doi: 10.1523/JNEUROSCI.3432-04.2004

Lacor, P. N., Buniel, M. C., Furlow, P. W., Clemente, A. S., Velasco, P. T., Wood, M., et al. (2007). A $\beta$ oligomer-induced aberrations in synapse composition, shape and density provide a molecular basis for loss of connectivity in Alzheimer's disease. J. Neurosci. 27, 796-807. doi: 10.1523/JNEUROSCI.3501-06.2007

Lambert, M. P., Barlow, A. K., Chromy, B. A., Edwards, C., Freed, R., Liosatos, M., et al. (1998). Diffusible, nonfibrillar ligands derived from $A \beta-42$ are potent central nervous system neurotoxins. Proc. Natl. Acad. Sci. U S A 95, 6448-6453. doi: 10.1073/pnas.95.11.6448

Lantz, K. A., Hart, S. G., Planey, S. L., Roitman, M. F., Ruiz-White, I. A., Wolfe, H. R., et al. (2010). Inhibition of PTP1B by trodusquemine (MSI1436) causes fat-specific weight loss in diet-induced obese mice. Obesity (Silver Spring) 18, 1516-1523. doi: 10.1038/oby.2009.444

Leal, G., Afonso, P. M., Salazar, I. L., and Duarte, C. B. (2015). Regulation of hippocampal synaptic plasticity by BDNF. Brain Res. 1621, 82-101. doi: 10.1016/j.brainres.2014.10.019

Ledo, J. H., Azevedo, E. P., Beckman, D., Ribeiro, F. C., Santos, L. E., Razolli, D., et al. (2016). Crosstalk between brain innate immunity and serotonin signaling underlies depressive-like behavior induced by Alzheimer's amyloid- $\beta$ oligomers in mice. J. Neurosci. 36, 12106-12116. doi: 10.1523/JNEUROSCI. 1269-16.2016

Ledo, J. H., Azevedo, E. P., Clarke, J. R., Ribeiro, F. C., Figueiredo, C. P., Foguel, D., et al. (2013). Amyloid- $\beta$ oligomers link depressive-like behavior and cognitive deficits in mice. Mol. Psychiatry 18, 1053-1054. doi: 10.1038/mp.2012.168

Lindtner, C., Scherer, T., Zielinski, E., Filatova, N., Fasshauer, M., Tonks, N. K., et al. (2013). Binge drinking induces whole-body insulin resistance by impairing hypothalamic insulin action. Sci. Transl. Med. 5:170ra114. doi: $10.1126 /$ scitranslmed.3005123

Lourenco, M. V., Clarke, J. R., Frozza, R. L., Bomfim, T. R., Forny-Germano, L., Batista, A. F., et al. (2013). TNF- $\alpha$ mediates PKR-dependent memory impairment and brain IRS-1 inhibition induced by Alzheimer's $\beta$-amyloid oligomers in mice and monkeys. Cell Metab. 18, 831-843. doi: 10.1016/j.cmet. 2013.11.002

Lourenco, M. V., Ferreira, S. T., and De Felice, F. G. (2015). Neuronal stress signaling and eIF $2 \alpha$ phosphorylation as molecular links between Alzheimer's disease and diabetes. Prog. Neurobiol. 129, 37-57. doi: 10.1016/j.pneurobio. 2015.03.003

Lui, H., Zhang, J., Makinson, S. R., Cahill, M. K., Kelley, K. W., Huang, H. Y., et al. (2016). Progranulin deficiency promotes circuit-specific synaptic pruning by microglia via complement activation. Cell 165, 921-935. doi: 10.1016/j.cell. 2016.04.001

Ma, Q.-L., Yang, F., Rosario, E. R., Ubeda, O. J., Beech, W., Gant, D. J., et al. (2009). $\beta$-amyloid oligomers induce phosphorylation of tau and inactivation of insulin receptor substrate via c-Jun $\mathrm{N}$-terminal kinase signaling: suppression by omega-3 fatty acids and curcumin. J. Neurosci. 29, 9078-9089. doi: 10.1523/JNEUROSCI.1071-09.2009

Maioli, S., Lodeiro, M., Merino-Serrais, P., Falahati, F., Khan, W., Puerta, E., et al. (2015). Alterations in brain leptin signalling in spite of unchanged CSF leptin levels in Alzheimer's disease. Aging Cell 14, 122-129. doi: 10.1111/acel.12281

Malamas, M. S., Sredy, J., Gunawan, I., Mihan, B., Sawicki, D. R., Seestaller, L., et al. (2000). New azolidinediones as inhibitors of protein tyrosine phosphatase 1B with antihyperglycemic properties. J. Med. Chem. 43, 995-1010. doi: $10.1021 / \mathrm{jm} 990476 \mathrm{x}$

Marwarha, G., Dasari, B., Prabhakara, J. P., Schommer, J., and Ghribi, O. (2010). $\beta$-Amyloid regulates leptin expression and tau phosphorylation through the mTORC1 signaling pathway. J. Neurochem. 115, 373-384. doi: 10.1111/j.14714159.2010.06929.x

Marwarha, G., Prasanthi, J. R., Schommer, J., Dasari, B., and Ghribi, O. (2011). Molecular interplay between leptin, insulin-like growth factor- 1 and $\beta$-amyloid 
in organotypic slices from rabbit hippocampus. Mol. Neurodegener. 6:41. doi: 10.1186/1750-1326-6-41

McClean, P. L., Parthsarathy, V., Faivre, E., and Holscher, C. (2011). The diabetes drug liraglutide prevents degenerative processes in a mouse model of Alzheimer's disease. J. Neurosci. 31, 6587-6594. doi: 10.1523/JNEUROSCI. 0529-11.2011

Mercer, J. G., Hoggard, N., Williams, L. M., Lawrence, C. B., Hannah, L. T., and Trayhurn, P. (1996). Localization of leptin receptor mRNA and the long form splice variant ( $\mathrm{Ob}-\mathrm{Rb})$ in mouse hypothalamus and adjacent brain regions by in situ hybridization. FEBS Lett. 387, 113-116. doi: 10.1016/00145793(96)00473-5

Morton, G. J., Cummings, D. E., Baskin, D. G., Barsh, G. S., and Schwartz, M. W. (2006). Central nervous system control of food intake and body weight. Nature 443, 289-295. doi: 10.1038/nature05026

Nagahara, A. H., Merrill, D. A., Coppola, G., Tsukada, S., Schroeder, B. E., Shaked, G. M., et al. (2009). Neuroprotective effects of brain-derived neurotrophic factor in rodent and primate models of Alzheimer's disease. Nat. Med. 15, 331-337. doi: 10.1038/nm.1912

Ott, A., Stolk, R. P., Hofman, A., van Harskamp, F., Grobbee, D. E., and Breteler, M. M. (1996). Association of diabetes mellitus and dementia: the Rotterdam study. Diabetologia 39, 1392-1397. doi: 10.1007/s0012500 50588

Owen, C., Lees, E. K., Grant, L., Zimmer, D. J., Mody, N., Bence, K. K., et al. (2013). Inducible liver-specific knockdown of protein tyrosine phosphatase 1B improves glucose and lipid homeostasis in adult mice. Diabetologia 56, 2286-2296. doi: 10.1007/s00125-013-2992-Z

Ozek, C., Kanoski, S. E., Zhang, Z. Y., Grill, H. J., and Bence, K. K. (2014). Protein-tyrosine phosphatase 1B (PTP1B) is a novel regulator of central brain-derived neurotrophic factor and tropomyosin receptor kinase B (TrkB) signaling. J. Biol. Chem. 289, 31682-31692. doi: 10.1074/jbc.M114. 603621

Pandey, N. R., Zhou, X., Qin, Z., Zaman, T., Gomez-Smith, M., Keyhanian, K., et al. (2013). The LIM domain only 4 protein is a metabolic responsive inhibitor of protein tyrosine phosphatase $1 \mathrm{~B}$ that controls hypothalamic leptin signaling. J. Neurosci. 33, 12647-12655. doi: 10.1523/JNEUROSCI.074613.2013

Pandey, N. R., Zhou, X., Zaman, T., Cruz, S. A., Qin, Z., Lu, M., et al. (2014). LMO4 is required to maintain hypothalamic insulin signaling. Biochem. Biophys. Res. Commun. 450, 666-672. doi: 10.1016/j.bbrc.2014. 06.026

Panzhinskiy, E., Ren, J., and Nair, S. (2013). Protein tyrosine phosphatase 1B and insulin resistance: role of endoplasmic reticulum stress/reactive oxygen species/nuclear factor kappa B axis. PLoS One 8:e77228. doi: 10.1371/journal. pone. 0077228

Pei, J. J., Sersen, E., Iqbal, K., and Grundke-Iqbal, I. (1994). Expression of protein phosphatases (PP-1, PP-2A, PP-2B and PTP-1B) and protein kinases (MAP kinase and P34cdc2) in the hippocampus of patients with Alzheimer disease and normal aged individuals. Brain Res. 655, 70-76. doi: 10.1016/00068993(94)91598-9

Peng, S., Wuu, J., Mufson, E. J., and Fahnestock, M. (2005). Precursor form of brain-derived neurotrophic factor and mature brain-derived neurotrophic factor are decreased in the pre-clinical stages of Alzheimer's disease. J. Neurochem. 93, 1412-1421. doi: 10.1111/j.1471-4159.2005. 03135.x

Phillips, H. S., Hains, J. M., Armanini, M., Laramee, G. R., Johnson, S. A., and Winslow, J. W. (1991). BDNF mRNA is decreased in the hippocampus of individuals with Alzheimer's disease. Neuron 7, 695-702. doi: 10.1016/08966273(91)90273-3

Popov, D. (2012). Endoplasmic reticulum stress and the on site function of resident PTP1B. Biochem. Biophys. Res. Commun. 422, 535-538. doi: 10.1016/j.bbrc. 2012.05.048

Qi, Z. G., Zhao, X., Zhong, W., and Xie, M. L. (2016). Osthole improves glucose and lipid metabolism via modulation of PPAR $\alpha / \gamma$-mediated target gene expression in liver, adipose tissue and skeletal muscle in fatty liver rats. Pharm. Biol. 54, 882-888. doi: 10.3109/13880209.2015.1089295

Qin, Z., Pandey, N. R., Zhou, X., Stewart, C. A., Hari, A., Huang, H., et al. (2015a). Functional properties of Claramine: a novel PTP1B inhibitor and insulin-mimetic compound. Biochem. Biophys. Res. Commun. 458, 21-27. doi: $10.1016 /$ j.bbrc.2015.01.040
Qin, Z., Zhou, X., Pandey, N. R., Vecchiarelli, H. A., Stewart, C. A., Zhang, X., et al. (2015b). Chronic stress induces anxiety via an amygdalar intracellular cascade that impairs endocannabinoid signaling. Neuron 85, 1319-1331. doi: 10.1016/j. neuron.2015.02.015

Rafii, M. S., and Aisen, P. S. (2015). Advances in Alzheimer's disease drug development. BMC Med. 13:62. doi: 10.1186/s12916-015-0297-4

Ransohoff, R. M. (2016). How neuroinflammation contributes to neurodegeneration. Science 353, 777-783. doi: 10.1126/science.aag2590

Santos, L. E., Beckman, D., and Ferreira, S. T. (2016). Microglial dysfunction connects depression and Alzheimer's disease. Brain Behav. Immun. 55, 151-165. doi: 10.1016/j.bbi.2015.11.011

Scott, M. M., Lachey, J. L., Sternson, S. M., Lee, C. E., Elias, C. F., Friedman, J. M., et al. (2009). Leptin targets in the mouse brain. J. Comp. Neurol. 514, 518-532. doi: $10.1002 /$ cne. 22025

Selkoe, D. J., and Hardy, J. (2016). The amyloid hypothesis of Alzheimer's disease at 25 years. EMBO Mol. Med. 8, 595-608. doi: 10.15252/emmm. 201606210

Song, G. J., Jung, M., Kim, J. H., Park, H., Rahman, M. H., Zhang, S., et al. (2016). A novel role for protein tyrosine phosphatase $1 \mathrm{~B}$ as a positive regulator of neuroinflammation. J. Neuroinflammation 13:86. doi: 10.1186/s12974-0160545-3

Soontornniyomkij, V., Wang, G., Pittman, C. A., Hamilton, R. L., Wiley, C. A., and Achim, C. L. (1999). Absence of brain-derived neurotrophic factor and trkB receptor immunoreactivity in glia of Alzheimer's disease. Acta Neuropathol. 98, 345-348. doi: 10.1007/s004010051092

Sun, S., Zhang, H., Liu, J., Popugaeva, E., Xu, N. J., Feske, S., et al. (2014). Reduced synaptic STIM2 expression and impaired store-operated calcium entry cause destabilization of mature spines in mutant presenilin mice. Neuron 82, 79-93. doi: 10.1016/j.neuron.2014.02.019

Talbot, K., Wang, H. Y., Kazi, H., Han, L. Y., Bakshi, K. P., Stucky, A., et al. (2012). Demonstrated brain insulin resistance in Alzheimer's disease patients is associated with IGF-1 resistance, IRS-1 dysregulation and cognitive decline. J. Clin. Invest. 122, 1316-1338. doi: 10.1172/JCI59903

Tamrakar, A. K., Maurya, C. K., and Rai, A. K. (2014). PTP1B inhibitors for type 2 diabetes treatment: a patent review (2011-2014). Expert Opin. Ther. Pat. 24, 1101-1115. doi: 10.1517/13543776.2014.947268

Tautz, L. (2015). PTP1B: a new therapeutic target for Rett syndrome. J. Clin. Invest. 125, 2931-2934. doi: 10.1172/JCI83192

Tong, L., Balazs, R., Thornton, P. L., and Cotman, C. W. (2004). $\beta$-amyloid peptide at sublethal concentrations downregulates brain-derived neurotrophic factor functions in cultured cortical neurons. J. Neurosci. 24, 6799-6809. doi: 10.1523/JNEUROSCI.5463-03.2004

Tonks, N. K. (2013). Protein tyrosine phosphatases-from housekeeping enzymes to master regulators of signal transduction. FEBS J. 280, 346-378. doi: $10.1111 /$ febs.12077

Walsh, D. M., Klyubin, I., Fadeeva, J. V., Cullen, W. K., Anwyl, R., Wolfe, M. S., et al. (2002). Naturally secreted oligomers of amyloid $\beta$ protein potently inhibit hippocampal long-term potentiation in vivo. Nature 416, 535-539. doi: $10.1038 / 416535$ a

Wang, W. Y., Tan, M. S., Yu, J. T., and Tan, L. (2015). Role of pro-inflammatory cytokines released from microglia in Alzheimer's disease. Ann. Transl. Med. 3:136. doi: 10.3978/j.issn.2305-5839.2015.03.49

Wang, N., Zhang, D., Mao, X., Zou, F., Jin, H., and Ouyang, J. (2009). Astragalus polysaccharides decreased the expression of PTP1B through relieving ER stress induced activation of ATF6 in a rat model of type 2 diabetes. Mol. Cell. Endocrinol. 307, 89-98. doi: 10.1016/j.mce.2009.03.001

Wes, P. D., Sayed, F. A., Bard, F., and Gan, L. (2016). Targeting microglia for the treatment of Alzheimer's disease. Glia 64, 1710-1732. doi: 10.1002/glia.22988

Xu, H., Gelyana, E., Rajsombath, M., Yang, T., Li, S., and Selkoe, D. (2016). Environmental enrichment potently prevents microglia-mediated neuroinflammation by human amyloid $\beta$-protein oligomers. J. Neurosci. 36, 9041-9056. doi: 10.1523/JNEUROSCI.1023-16.2016

Yamada, T., Urano-Tashiro, Y., Hashi, Y., Sakumoto, M., Akiyama, H., and Tashiro, F. (2013). The U-box-type ubiquitin ligase PRP19 $\beta$ regulates astrocyte differentiation via ubiquitination of PTP1B. Brain Res. 1524, 12-25. doi: 10.1016/j.brainres.2013.06.007

Yu, I.-C., Lin, H.-Y., Liu, N.-C., Sparks, J. D., Yeh, S., Fang, L.-Y., et al. (2013). Neuronal androgen receptor regulates insulin sensitivity via suppression of hypothalamic NF-кB-mediated PTP1B expression. Diabetes 62, 411-423. doi: $10.2337 / \mathrm{db} 12-0135$ 
Zabolotny, J. M., Bence-Hanulec, K. K., Stricker-Krongrad, A., Haj, F., Wang, Y., Minokoshi, Y., et al. (2002). PTP1B regulates leptin signal transduction in vivo. Dev. Cell 2, 489-495. doi: 10.1016/s1534-5807(02)00148-х

Zabolotny, J. M., Kim, Y. B., Welsh, L. A., Kershaw, E. E., Neel, B. G., and Kahn, B. B. (2008). Protein-tyrosine phosphatase 1B expression is induced by inflammation in vivo. J. Biol. Chem. 283, 14230-14241. doi: 10.1074/jbc. M800061200

Zhang, Z. Y., Dodd, G. T., and Tiganis, T. (2015). Protein tyrosine phosphatases in hypothalamic insulin and leptin signaling. Trends Pharmacol. Sci. 36, 661-674. doi: 10.1016/j.tips.2015.07.003

Zhang, Z. Y., and Lee, S. Y. (2003). PTP1B inhibitors as potential therapeutics in the treatment of type 2 diabetes and obesity. Expert Opin. Investig. Drugs 12, 223-233. doi: 10.1517/eoid.12.2.223.21411

Zhang, Y., Proenca, R., Maffei, M., Barone, M., Leopold, L., and Friedman, J. M. (1994). Positional cloning of the mouse obese gene and its human homologue. Nature 372, 425-432. doi: 10.1038/372425a0

Zhang, H., Wu, L., Pchitskaya, E., Zakharova, O., Saito, T., Saido, T., et al. (2015). Neuronal store-operated calcium entry and mushroom spine loss in amyloid precursor protein knock-in mouse model of Alzheimer's disease. J. Neurosci. 35, 13275-13286. doi: 10.1523/JNEUROSCI.1034-15.2015
Zhao, W. Q., De Felice, F. G., Fernandez, S., Chen, H., Lambert, M. P., Quon, M. J., et al. (2008). Amyloid beta oligomers induce impairment of neuronal insulin receptors. FASEB J. 22, 246-260. doi: 10.1096/fj.06-7703com

Zinker, B. A., Rondinone, C. M., Trevillyan, J. M., Gum, R. J., Clampit, J. E., Waring, J. F., et al. (2002). PTP1B antisense oligonucleotide lowers PTP1B protein, normalizes blood glucose and improves insulin sensitivity in diabetic mice. Proc. Natl. Acad. Sci. U S A 99, 11357-11362. doi: 10.1073/pnas. 142298199

Conflict of Interest Statement: The authors declare that the research was conducted in the absence of any commercial or financial relationships that could be construed as a potential conflict of interest.

Copyright (C) 2017 Vieira, Lyra e Silva, Ferreira and De Felice. This is an open-access article distributed under the terms of the Creative Commons Attribution License (CC BY). The use, distribution and reproduction in other forums is permitted, provided the original author(s) or licensor are credited and that the original publication in this journal is cited, in accordance with accepted academic practice. No use, distribution or reproduction is permitted which does not comply with these terms. 